\title{
BMJ Open Diseases with oral manifestations among adult asthmatics in Finland: a population-based matched cohort study
}

\author{
Riikka Lemmetyinen (D) ,1,2 Jussi Karjalainen, 3,4 Anna But, ${ }^{2}$ Risto Renkonen, 5,6 \\ Juha Pekkanen, ${ }^{2,7}$ Jari Haukka (D) ,' Sanna Toppila-Salmi (i) ${ }^{8,9}$
}

To cite: Lemmetyinen $\mathrm{R}$, Karjalainen J, But A, et al. Diseases with oral manifestations among adult asthmatics in Finland: a population-based matched cohort study. BMJ Open 2021;11:e053133. doi:10.1136/ bmjopen-2021-053133

- Prepublication history for this paper is available online. To view these files, please visit the journal online (http://dx.doi. org/10.1136/bmjopen-2021053133).

Received 06 May 2021 Accepted 19 October 2021

Check for updates

(C) Author(s) (or their employer(s)) 2021. Re-use permitted under CC BY-NC. No commercial re-use. See rights and permissions. Published by BMJ.

For numbered affiliations see end of article.

Correspondence to Dr Riikka Lemmetyinen; riikka.lemmetyinen@helsinki.fi

\section{ABSTRACT}

Objectives Many comorbidities are associated with adult asthma and may exacerbate the asthma burden of disease. This study aims to investigate the risk for major oral diseases or oral-manifesting diseases in asthmatic compared with non-asthmatic adults.

Design We conducted a population-based matched cohort study with a 13.8-year follow-up.

Setting A baseline questionnaire was completed by participants in 1997 and follow-up data were extracted from the national hospital discharge registry of the National Institute for Health and Welfare in Finland from 1997 to 2014.

Participants A total of 1394 adults with asthma were matched with 2398 adults without asthma based on sex, age and area of residence. Asthmatic adults were identified from the Drug Reimbursement Register of the Finnish Social Insurance Institution based on a special drug reimbursement right resulting from asthma. Participants without asthma were identified from the Population Register.

Main outcomes and measures Oral health-related primary diagnoses were retrieved using codes from the International Classification of Diseases, 10th edition and divided into groups of diseases. Cox's proportional hazards models stratified by matching unit and models matched and adjusted for pack-years, education level and body mass index (when possible) were used to evaluate the matched and further adjusted HRs for diseases comparing asthmatic and non-asthmatic cohorts.

Results Adult asthma was associated with a higher risk for any oral-manifesting disease (adjusted HR 1.41, $95 \% \mathrm{Cl} 1.11$ to 1.80), herpes zoster (adjusted HR 6.18, $95 \% \mathrm{Cl} 1.21$ to 31.6 ), benign tumours of the oral cavity and pharynx (matched HR 1.94, 95\% Cl 1.05 to 3.56 ) and dermatological diseases (pemphigus, pemphigoid, dermatitis herpetiformis, psoriasis and lichen planus, HR $1.67,95 \% \mathrm{Cl} 1.01$ to 2.78 ).

Conclusions In this study, adult asthmatics experienced a higher risk for a major oral disease or oral-manifesting disease.

\section{INTRODUCTION}

Asthma is one of the most common chronic diseases in children and adults, recognised for its characteristic pattern of symptoms, such as its timing, triggers and response

\section{Strengths and limitations of this study}

This study is a population-based, matched cohort design with a nearly 14-year follow-up.

- A detection bias was possible given the more intensive use of healthcare services among asthmatics (and people with any moderate to severe chronic disease) compared with non-asthmatics, potentially impacting the results.

- The possible causal relationship between asthma and oral health conditions may be confounded by asthma medications, which decrease salivary flow and lower the $\mathrm{pH}$ in the oral cavity.

- An asthma diagnosis was confirmed by a medical doctor and based on lung function tests and typical medical history.

- The study lacks data from primary care, where common dental or oral problems, such as periodontitis or oral candidiasis, are typically treated.

to treatment. Typical symptoms include wheezing, shortness of breath, chest tightness and a cough, yet a careful patient history remains crucial for the differential diagnosis. The prevalence of asthma in adults ranges from $0.2 \%$ to $21.0 \%$, remaining highest in developed countries and most likely underestimated in poorer countries. ${ }^{1}$ In addition to socioeconomic class and a genetic predisposition, megatrends such as climate change, ageing and urbanisation impact asthma prevalence. ${ }^{2-4}$ While asthma has been considered a single disease, recent studies have shown that it consists of multiple phenotypes. ${ }^{5}$ Furthermore, asthma varies considerably across a patient's life, presenting differently in adults vs children. Where childhood asthma is characterised by a predominance of allergic multimorbidity and a higher prevalence among boys, adult asthma is associated with more respiratory symptoms and asthma medications. ${ }^{6}$ Risk factors for adult asthma consist of a genetic predisposition, female gender, overweight, allergies, upper airway diseases and exposure to tobacco smoke or 
other irritants. ${ }^{7}$ The primary adult asthma phenotypes identified thus far include (1) early-onset allergic asthma, (2) early-onset allergic moderate-to-severe remodelled asthma, (3) late-onset no-nallergic eosinophilic asthma and (4) late-onset non-allergic non-eosinophilic asthma, whereby an overlap of commonly reported asthma phenotypes has also been observed carrying implications for objective asthma outcomes. ${ }^{5}$ Furthermore, the definition of 'early onset' varies across studies. For instance, a study investigating severe asthma subgroups defined late-asthma onset as occurring after the age of 12 years, ${ }^{9}$ while other studies refer to early-onset adult asthma when asthma onset was reported at $12-15$ years. ${ }^{10}$ More severe forms of adult asthma appear less stable than childhoodonset disease with more relapses and less remission, and have been associated with an increased IgE, eosinophilia, poorer adherence to therapy, recurrent infections, obesity, smoking and a lower socioeconomic status. ${ }^{16}$ Various classifications and subgroups of asthma phenotypes have been proposed, but a clear consensus has not yet emerged within the scientific community. The heterogeneity of severe asthma phenotypes has resulted in the development of new asthma treatments targeting specific immune pathways, with perhaps a limited utility among the general asthma population, but carrying a potential benefit to a subset of asthma patients. ${ }^{11}$

Studies have demonstrated that many comorbidities coexist with asthma, possibly even contributing to a lower life expectancy. ${ }^{12}$ We previously detected an increased all-cause mortality among asthmatics in the Finnish adult population, largely explained by the development of chronic obstructive pulmonary disease in smoking asthmatics, malignant respiratory tract neoplasms and cardiovascular diseases. ${ }^{13}$ In the Finnish population, the most common comorbidities of adult asthma consist of hypertension, diabetes, severe psychiatric disorders and ischaemic heart disease. ${ }^{14}$ Other known asthma-related comorbidities include rhinitis, chronic sinusitis, gastrooesophageal reflux disease, obstructive sleep apnoea, hormonal disorders, obesity, hyperventilation, glottic dysfunction and respiratory infections. ${ }^{15}$ In a populationbased cross-sectional study covering 1.4 million Scottish patients, comorbidities associated with asthma in adults included chronic obstructive pulmonary disease, bronchiectasis, eczema/psoriasis, dyspepsia, depression and anxiety. ${ }^{16}$

Asthma was previously associated with herpes zoster, tooth decay, dental erosion, oral candidiasis, periodontal disease, psoriasis and gastro-oesophageal reflux disease. ${ }^{16-25}$ A cross-sectional, self-reported study investigated the association of oral health and asthma/ allergic rhinitis/atopic dermatitis in a large population of Korean adolescents over a 12 -month period. ${ }^{26}$ Poor oral health was significantly correlated with the prevalence of asthma/allergic rhinitis/atopic dermatitis. That study benefited from a large sample of over 130000 participants, although the assessment of causality was limited due to its cross-sectional design. ${ }^{26}$ The oral cavity is closely connected with the lower airways given the anatomical location and in terms of functions such as conducting and modifying inhaled air and speech. A recent review outlined one theory suggesting that the lung microbiota results from the random immigration of bacteria originally from the oral microbiota, random bacterial reproduction in the lung and the random exclusion of lung bacteria. ${ }^{27}$ That same review suggested that associations between asthma and oral health are explained by asthma medications, mainly $\beta_{2}$-agonists and inhaled steroids. Specifically, asthma inhalers decrease saliva production and its components, which protect and rinse the oral cavity and teeth. They also contain sugary components and create a $\mathrm{pH}<5.5$, thus inducing dental caries and erosion. ${ }^{27} 28$ The direct effects of asthma on periodontal health may involve dehydrating the alveolar mucosa due to mouth breathing, and altering the immune response via an increased concentration of IgE, which may cause periodontal destruction. ${ }^{25}{ }^{29}$ Furthermore, obesity is a major risk factor for asthma, and closely connected to overeating and the high consumption of sweet foods and drinks, possibly leading to poor oral health. ${ }^{2530}$

\section{Study aim}

This cohort study aimed to investigate the hazard rate of major oral-manifesting diseases in asthmatic adults compared with non-asthmatic adults. We hypothesised that asthmatics experience more major oral diseases than non-asthmatics.

\section{METHODS \\ Study design}

This population-based, matched cohort study with follow-up began with a questionnaire completed in 1997, which collected data from asthmatics and matched nonasthmatics on their living environment, allergies, smoking duration and quantity, weight and education level. The questionnaire was sent to 4958 individuals, 3792 of whom responded. Altogether, this study consisted of 1394 asthmatics and 2398 adults without asthma. Follow-up data including all diagnostics codes for the participants who responded were collected from the national hospital discharge registry of the National Institute for Health and Welfare from 1997 to 2014.

\section{Patient and public involvement}

Study participants were not involved in planning the study design. Extended data from the registers were collected with approval from the National Institute for Health and Welfare. Study results have been published only in peerreviewed journals, with no other information related to the results provided to participants.

\section{Study population}

Participants with and without asthma were matched based on sex, age ( \pm 2 years) and area of residence by postal code. A total of 1400 asthmatic adults were 
Table 1 Baseline characteristics collected from Finnish patients via questionnaire in 1997

\begin{tabular}{|c|c|c|c|}
\hline & $\begin{array}{l}\text { No } \\
\text { asthma, } \mathrm{n} \\
\text { (\%) }\end{array}$ & $\begin{array}{l}\text { Asthma, } n \\
(\%)\end{array}$ & $\begin{array}{l}\text { Missing } \\
(\%)\end{array}$ \\
\hline \multicolumn{4}{|l|}{ Sex } \\
\hline Men & $912(38.0)$ & $532(38.2)$ & \\
\hline Women & $1486(62.0)$ & $862(61.8)$ & \\
\hline Total & 2398 & 1394 & \\
\hline \multicolumn{4}{|l|}{ Age at baseline (in years) } \\
\hline$\leq 59$ & $1506(62.8)$ & $893(64.1)$ & \\
\hline $60-69$ & $699(29.1)$ & $401(28.8)$ & \\
\hline $70-79$ & $166(6.9)$ & $84(6.0)$ & \\
\hline$\geq 80$ & $27(1.1)$ & $16(1.1)$ & \\
\hline Pack-years & & & 6.7 \\
\hline 0 & $1286(57.1)$ & 625 (48.6) & \\
\hline$\leq 19$ & $595(26.4)$ & $389(30.2)$ & \\
\hline$\geq 20$ & $371(16.5)$ & $273(21.2)$ & \\
\hline 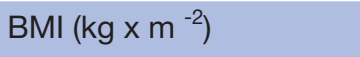 & & & 2.4 \\
\hline Underweight (<18.5) & $26(1.1)$ & $19(1.4)$ & \\
\hline Normal (18.5-24.99) & 998 (42.6) & $463(34.0)$ & \\
\hline Overweight (25-29.99) & 958 (40.9) & $577(42.4)$ & \\
\hline Obese $(\geq 30)$ & $358(15.3)$ & $303(22.2)$ & \\
\hline Education level & & & 2.2 \\
\hline Matriculation exam & 435 (18.5) & $187(13.8)$ & \\
\hline Secondary school & $560(23.8)$ & $322(23.7)$ & \\
\hline Primary school or less & $1356(57.7)$ & $850(62.5)$ & \\
\hline
\end{tabular}

Lifetime tobacco exposure was calculated in pack-years (number of cigarettes per day/20xnumber of years smoked, where 1 pipe $=2.5$ cigarettes and 1 cigar $=4$ cigarettes) on which individuals were divided into three groups: $0, \leq 19$ and $\geq 20$ pack-years. $\mathrm{BMl}$ assessed as weight in kilograms divided by the square of the height in metres, then divided into four categories according to WHO classification.

Level of education was obtained through a questionnaire and categorised based on the Finnish education system: matriculation examination (13 years, reference value), secondary school or equivalent (9 years) and primary school or less ( $\leq 6$ years). BMI, body mass index.

identified from the Drug Reimbursement Register of the Finnish Social Insurance Institution based on a special drug reimbursement right due to an asthma diagnosis. The population register was used to identify 2800 matched non-asthmatics. In total, 248 asthmatics and 511 non-asthmatics were recruited from the Mini Finland Health Survey. ${ }^{31}$ All asthmatics fulfilled the criteria for physician-diagnosed asthma, criteria which included a typical history, clinical features and asthma course and lung function tests. Participants were over 30 years old (table 1 ), nearly $62 \%$ were male and $38 \%$ women. An estimate of participants' lifetime tobacco exposure at baseline was calculated in pack-years. ${ }^{32}$ The body mass index was grouped according to four categories, while level of education was divided into three categories based on the Finnish education system. The study population was described in further detail elsewhere. ${ }^{13}$

\section{Outcomes}

In this study, we focused on oral diseases and diagnoses that can manifest in the oral cavity. The diagnoses were identified from hospital visit and hospitalisation data obtained from the national hospital discharge registry of the National Institute for Health and Welfare from 1997 to 2014. Only the primary diagnoses were retrieved using codes from the International Classification of Diseases, 10th edition (ICD-10), and were divided into five disease groups: infections, malign neoplasms, benign neoplasms, dental diseases and dermatological diseases. The first group consisted of viral and fungal infections (herpes simplex (B00.1); herpes zoster (B02); hand, foot and mouth disease (B08.4); herpangina (B08.5); HIV disease resulting in candidiasis (B20.4); Kaposi sarcoma (B21.0); Burkitt lymphoma (B21.1); mumps (B26.9); Epstein-Barr (B27.0); candidiasis (B37); and tonsillar aspergillosis (B44.2). Malign neoplasms consisted of malignant neoplasms of the lip, oral cavity and pharynx (C00-C14); malignant melanoma of the lip (C43.0) and basal cell carcinoma of the lip (C44.0). Benign neoplasms included benign tumours (D00.0, D03.0 and D03.3), in situ neoplasms (D23.0) and other benign neoplasms of the lip, oral cavity, pharynx or bone of the skull and face (D10, D11, D16.4, D16.5 and D37.0). Dental diseases included diseases of the oral cavity, salivary glands and jaws (K00-K14). The last group included dermatological diseases (pemphigus L10), pemphigoid (L12), dermatitis herpetiformis (L13.0), psoriasis (L40) and lichen planus (L43).

We used a 1-year wash-out period from the beginning of follow-up in 1997 to identify and exclude those with a preexisting disease of interest. For each outcome of interest, those eligible for follow-up (eg, individuals without diagnoses during the wash-out period) were followed up until the first occurrence defined as the first hospital visit/ hospitalisation with a diagnosis of interest, death or the end of follow-up (31 December 2014). Therefore, each diagnosis was recorded only once.

\section{Statistical analyses}

We assessed and reported the incidence of the diseases of interest. Cox proportional hazards models stratified by the matching criteria (sex, age and area of residence by postal code) and models matched and adjusted for smoking, education level and body mass index (when possible) were used to evaluate the matched and additionally adjusted HRs for diseases comparing asthmatic and non-asthmatic individuals. We modelled each comorbidity separately. The differences in comorbidity-free survival between asthmatics and non-asthmatics were also assessed by plotting the Kaplan-Meier survival curves and performing log-rank tests. In all analyses, we considered $\mathrm{p}<0.05$ statistically significant. All data analyses 
Table 2 Comparison of Finnish non-asthmatic and asthmatic adults for oral comorbidities, 1997-2014

\begin{tabular}{|c|c|c|c|c|c|c|}
\hline & & $\begin{array}{l}10000 \\
\text { person- } \\
\text { years }\end{array}$ & Events & $\begin{array}{l}\text { Rate }(95 \% \mathrm{Cl}) \text { per } \\
10000 \text { person- } \\
\text { years }\end{array}$ & Matched HR $(95 \% \mathrm{Cl})$ & Adjusted HR (95\% Cl) \\
\hline \multirow[t]{2}{*}{ Any oral disease } & No asthma & 33.46 & 165 & 4.93 (4.21 to 5.74 ) & 1 & 1 \\
\hline & Asthma & 18.41 & 136 & 7.39 (6.20 to 8.74 ) & 1.61 (1.24 to 2.10$)$ & $1.41(1.11 \text { to } 1.80)^{\star}$ \\
\hline \multirow[t]{2}{*}{ Herpes zoster } & No asthma & 34.72 & 4 & 0.11 (0.03 to 0.29$)$ & 1 & 1 \\
\hline & Asthma & 19.51 & 14 & 0.72 (0.39 to 1.20$)$ & 6.94 (1.50 to 32.1$)$ & $6.18(1.21$ to 31.6$) \dagger$ \\
\hline \multirow[t]{2}{*}{ Malign neoplasms } & No asthma & 34.66 & 11 & 0.32 (0.16 to 0.57$)$ & 1 & 1 \\
\hline & Asthma & 19.52 & 13 & 0.67 (0.35 to 1.14$)$ & 2.33 (0.91 to 5.99$)$ & $2.13(0.72$ to 6.34$) \dagger$ \\
\hline \multirow[t]{2}{*}{ Benign neoplasms } & No asthma & 34.53 & 28 & 0.81 (0.54 to 1.17$)$ & 1 & 1 \\
\hline & Asthma & 19.41 & 25 & 1.29 (0.83 to 1.90$)$ & 1.94 (1.05 to 3.56$)$ & $1.64(0.81$ to 3.33$) \ddagger$ \\
\hline \multirow[t]{2}{*}{ Dental diseases } & No asthma & 34.02 & 96 & 2.82 (2.29 to 3.45 ) & 1 & 1 \\
\hline & Asthma & 19.03 & 66 & 3.47 (2.68 to 4.41$)$ & 1.21 (0.84 to 1.73$)$ & 1.40 (0.93 to 2.12$) \dagger \dagger$ \\
\hline \multirow{2}{*}{$\begin{array}{l}\text { Dermatological } \\
\text { diseases }\end{array}$} & No asthma & 34.35 & 42 & $1.22(0.88$ to 1.65$)$ & 1 & 1 \\
\hline & Asthma & 19.19 & 36 & 1.88 (1.31 to 2.60$)$ & 1.67 (1.01 to 2.78$)$ & $1.72(0.85 \text { to } 3.47)^{\star}$ \\
\hline
\end{tabular}

HR based on Cox proportional hazards regression models. In the first model, matching is considered as strata. The second model is matched and adjusted based on background variables.

Matched HR, participants with asthma and without asthma are only matched for sex, age and area of residence by postal code. Bold values denote statistical significance at the $p<0.05$ level.

Adjusted HRs.

*Matched for sex, age and area of residence by postal code and adjusted for pack-years, education level and body mass index. †Matched for sex, age and area of residence by postal code and adjusted for pack-years.

$\ddagger$ Matched for sex, age and area of residence by postal code and adjusted for pack-years and education level.

were performed using the R statistical software package, V.3.6.1..$^{33}$

\section{RESULTS}

The mean follow-up period was 13.8 years. A total of 58113 person-years accumulated for 3792 individuals. Overall, $71 \%$ of asthmatic patients used inhaled corticosteroids and $76 \%$ used any inhaled asthma medication at baseline (in 1997). The risk of experiencing any oral health-related disease (including all diseases investigated) was higher among asthmatics (matched HR 1.61, 95\% CI 1.24 to 2.10, p<0.001, table 2), with the KaplanMeier plot (figure 1) showing a clear difference between asthmatics and non-asthmatics individuals. These results remained significant after adjusting for pack-years, education level and body mass index (HR 1.41, 95\% CI 1.11 to $1.80, \mathrm{p}=0.001$ ).

Only a few cases of candidiasis and herpes simplex infections were recorded in the infections group. Since these cases primarily consisted of herpes zoster, we calculated the HR for herpes zoster cases only. We found that the rate of herpes zoster was nearly seven times higher in the asthmatic group (matched HR 6.94, 95\% CI 1.50 to 32.1, $\mathrm{p}<0.05)$ compared with non-asthmatics. After adjusting for pack-years, this association persisted (adjusted HR $6.18,95 \%$ CI 1.21 to $31.6, \mathrm{p}<0.05)$. Benign tumours were 1.5 -fold more frequent among asthmatics (matched HR $1.94,95 \%$ CI 1.05 to $3.56, \mathrm{p}<0.05)$. The most common benign tumours in the head area included neoplasms of the inner mouth and tumours of the parotid gland and other major salivary glands.

Asthma was not significantly associated with an increased risk for malignant neoplasms of the lip, oral cavity or pharynx (matched HR 2.33, 95\% CI 0.91 to $5.99, \mathrm{p}=0.080$ ). Cancers of the lip, oral cavity or pharynx as well as melanoma or basal cell carcinoma of the lip were recorded. The risk for of non-neoplastic conditions of the head and neck region, in addition to diseases of the oral cavity, salivary glands and jaws was not significantly higher among asthmatics (HR 1.21, 95\% CI 0.84 to 1.73, $\mathrm{p}=0.059$ ). Similarly, dental diseases such as caries, chronic apical periodontitis and periapical abscess taken together were not significantly associated with adult asthma neither in a univariate analysis (matched HR 1.21, 95\% CI 0.84 to $1.73, \mathrm{p}=0.307$ ) nor after adjustment (HR 1.40, 95\% CI 0.93 to 2.12). A higher risk for dental caries on its own emerged among adult asthmatics (matched HR 2.13, $95 \%$ CI 0.90 to $5.05, \mathrm{p}=0.085$ ) but the association was not statistically significant.

Finally, we examined dermatological diseases that may have oral manifestations, finding that the investigated diseases associated with asthma in the matched cohort (matched HR 1.67, 95\% CI 1.01 to 2.78, $\mathrm{p}=0.048$ ). However, after adjusting for pack-years, education level and body mass index, the association diminished (adjusted HR 1.72, 95\% CI 0.85 to 3.47, $\mathrm{p}=0.129$ ). Psoriasis 


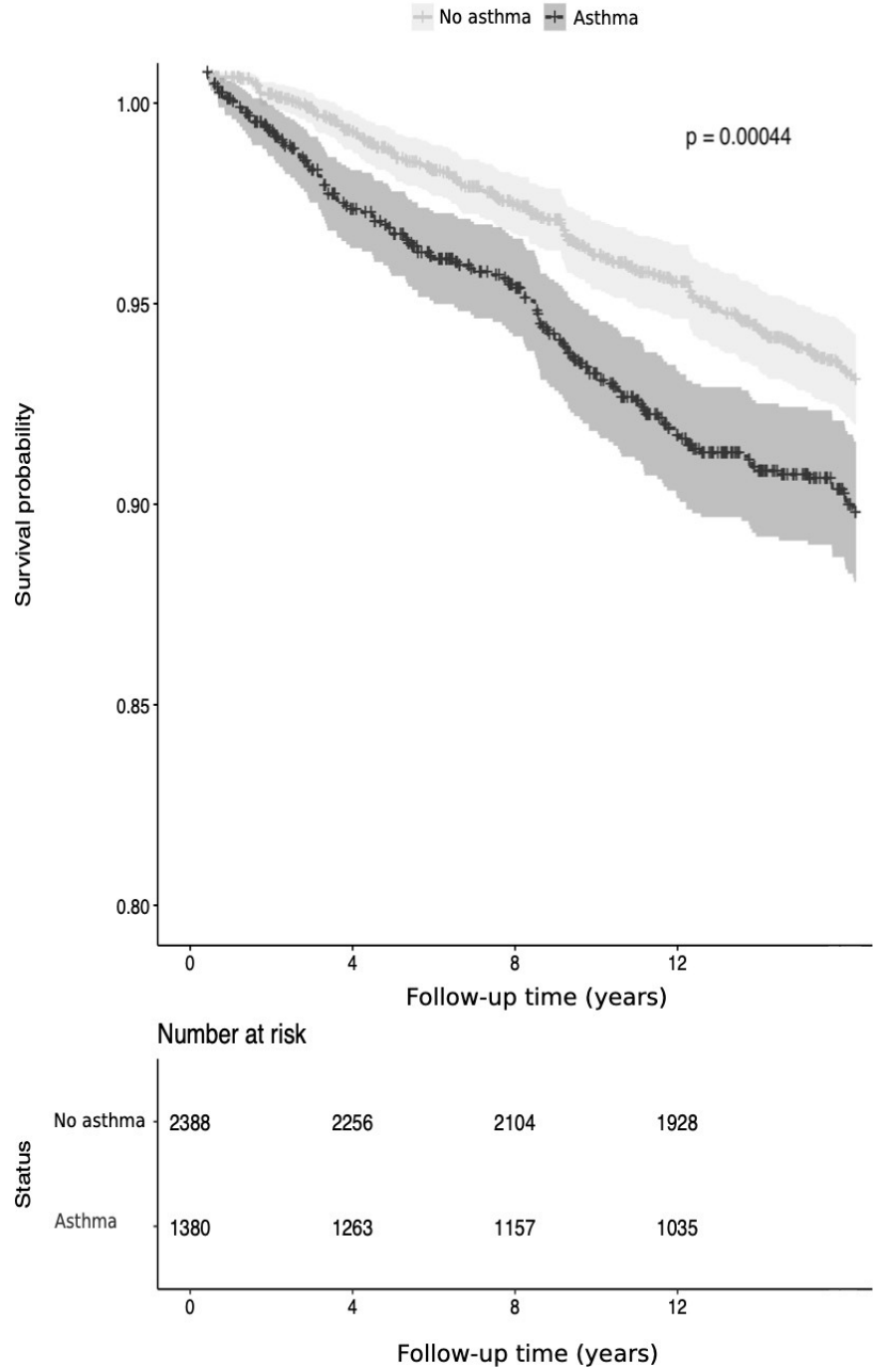

Figure 1 Kaplan-Meier survival curve of the difference in oral health-related diseases among asthmatics and nonasthmatics. $P$ value for the log-rank test.

and lichen planus were the most common skin diseases representing $89 \%$ of all skin diseases examined among asthmatic adults (table 3). Furthermore, among adults without asthma, psoriasis and lichen planus comprised $77 \%$ of all skin diseases investigated in this study. Other dermatological diseases identified included pemphigus, pemphigoid and dermatitis herpetiformis.

\section{DISCUSSION}

In this population-based, cohort study, asthmatics carried a higher risk of experiencing an oral-manifesting disease. The differences in the risks for infections, benign neoplasms and dermatological diseases contributed to the overall increase. The risk for benign oral tumours (including benign salivary gland tumours) was 1.5-fold higher, while the risk for a viral infection, specifically, herpes zoster, was nearly seven times higher among asthmatic adults compared with non-asthmatic adults. Dermatological diseases, mainly psoriasis and lichen planus,
Table 3 Frequency of oral diagnoses during follow-up, 1997-2014

\begin{tabular}{|c|c|c|}
\hline & No asthma & Asthma \\
\hline \multicolumn{3}{|l|}{ Virus infections } \\
\hline Herpes zoster (B02) & 4 & 14 \\
\hline Other infections (B00, B37) & 3 & 1 \\
\hline \multicolumn{3}{|l|}{ Oral cancer } \\
\hline $\begin{array}{l}\text { Lip, oral cavity and pharynx } \\
\text { (C00-C02, C04, C10, C13, C14) }\end{array}$ & 7 & 11 \\
\hline $\begin{array}{l}\text { Melanoma or basal cell } \\
\text { carcinoma of lip (C44) }\end{array}$ & 4 & 3 \\
\hline \multicolumn{3}{|l|}{ Benign tumours } \\
\hline Mouth and pharynx (D10) & 14 & 16 \\
\hline Major salivary glands (D11) & 8 & 8 \\
\hline $\begin{array}{l}\text { Other benign tumours (D03, D23, } \\
\text { D37) }\end{array}$ & 7 & 2 \\
\hline Dental diseases & 16 & 21 \\
\hline \multicolumn{3}{|l|}{ Dental caries (K01, K02) } \\
\hline $\begin{array}{l}\text { Diseases of the salivary glands } \\
\text { (K11) }\end{array}$ & 16 & 15 \\
\hline $\begin{array}{l}\text { Stomatitis and related lesions } \\
\text { (K12) }\end{array}$ & 6 & 5 \\
\hline $\begin{array}{l}\text { Diseases of the lip and oral } \\
\text { mucosa (K13) }\end{array}$ & 17 & 8 \\
\hline Diseases of the tongue (K14) & 8 & 5 \\
\hline $\begin{array}{l}\text { Other dental diseases (K03, K04, } \\
\mathrm{K} 10)\end{array}$ & 33 & 14 \\
\hline \multicolumn{3}{|l|}{ Dermatological diseases } \\
\hline Psoriasis (L40) & 21 & 22 \\
\hline Lichen planus (L43) & 13 & 12 \\
\hline Pemphigus (L10) & 1 & 0 \\
\hline Pemphigoid (L12) & 4 & 3 \\
\hline Dermatitis herpetiformis (L13.0) & 5 & 1 \\
\hline
\end{tabular}

associated with asthma in the matched cohort, although the risk was not significant in the adjusted model.

We observed an increased risk for herpes zoster among asthmatic adults. An 8-year follow-up study conducted in Taiwan among over 40000 newly diagnosed, adult asthmatics compared with age-matched and sex-matched non-asthmatics found that the risk of herpes zoster was 1.48-fold higher in asthmatics. ${ }^{34} \mathrm{~A}$ meta-analysis of 12 studies investigating the relationship between asthma and herpes zoster found that asthma was associated with a greater risk (risk ratio $1.24,95 \%$ CI 1.16 to 1.31 , $\mathrm{p}<0.0001)$ of infection. ${ }^{35}$ Herpes zoster infection in the intraoral region classically presents as a unilateral dermatomal rash with a maculopapular appearance, preceded with hard, neuropathic pain. ${ }^{36}$ Caused by the reactivation of varicella zoster virus, herpes zoster may occur spontaneously or due to an immune system deficiency. Respiratory viruses associated with asthma exacerbations 
include respiratory syncytial viru, influenza viruses and human rhinoviruses, as well as coronaviruses, parainfluenza viruses, adenoviruses and, more recently, metapneumoviruses and bocaviruses. ${ }^{389}$ Presumably, an age-related decline in immune function and a coexisting viral infection promotes persistent chronic inflammation of the airways. ${ }^{40}$

We previously found that a higher all-cause mortality among adult asthmatics was largely explained by the development of chronic obstructive pulmonary disease, malignant respiratory tract neoplasms and cardiovascular diseases. ${ }^{13}$ Although highly lethal in general, we detected no increased mortality resulting from oral cancer among asthmatics in our previous study, presumably due to its low incidence compared with other causes of death among both asthmatics and controls. In agreement with our previous findings, asthma did not significantly associate with malignant neoplasms of the oral cavity or pharynx in the study reported here.

Our results suggest that the risk of benign oral tumours could be higher among asthmatic adults compared with non-asthmatic adults. To our knowledge, this represents the first study to examine the association between benign oral tumours and asthma. Over 30\% of the benign tumours among asthmatics consisted of salivary gland tumours. While the cause of salivary gland tumours remains unknown, autoimmune conditions such as diabetes and Sjögren's syndrome are associated with salivary gland swelling. ${ }^{41}$ We suspect that the increased risk associated with benign oral tumours is explained by a combination of autoimmune dysfunction, decreased salivary flow (due to the use of $\beta_{2}$ agonists) and a detection bias resulting from the overdiagnosis of benign tumours among asthmatics, individuals who consult healthcare services more frequently.

Furthermore, we found that dental diseases (diseases including tooth decay, chronic apical periodontitis, sialadenitis and diseases of periodontal tissue) were not significantly associated with adult asthma. It is widely acknowledged that asthma medication, especially the immunosuppressive effects of inhaled corticosteroids, promote oral candidiasis and tooth decay. ${ }^{25}$ According to a meta-analysis and systematic review of 18 studies, asthma roughly doubles the risk of dental caries in both primary and permanent dentition. ${ }^{17}$ Plausible mechanisms contributing to tooth decay include decreased saliva secretion and a lower salivary $\mathrm{pH}$ due to inhaled $\beta_{2}$-agonists and corticosteroids as well as dry powder inhalers containing lactose monohydrate, and an increase in Lactobacilli and Streptococcus mutans in the oral cavity. ${ }^{1721}$ An increased risk for caries might also stem from the decreased biodiversity in the oral cavity and an aberrant immunity among asthmatics.

The data used in this study were collected from the national hospital discharge registry of the National Institute for Health and Welfare in Finland, which collects data from hospital and health centres. The dental or and/ oral diagnoses in this study result from dental specialists working in specialised healthcare settings. The National Institute for Health and Welfare of Finland began collecting outpatient data from public health services (such as data from dental examination) in 2011, and the initial years of data collection featured poor-quality data. Therefore, our data do not include oral status information routinely collected by dentists in primary care settings, and we cannot draw any conclusions about the incidence of, for example, tooth decay from these data. Additionally, oral candidiasis is presumably common among patients using inhaled corticosteroids. However, due to its mild symptoms, the condition often remains undiagnosed. In our study, only a few cases of oral candidiasis were recorded. Thus, a causal relationship between inhaled asthma medications and oral candidiasis could not be examined from these data.

In our study, dermatological diseases with potential oral manifestations were more common among asthmatics. Psoriasis is an immune-mediated, genetic skin and joint disease typically characterised by erythematosus plaques with silvery scales. ${ }^{23}$ A recent meta-analysis indicated that patients with psoriasis carry an increased risk for asthma, particularly older patients. ${ }^{22}$ Furthermore, oral manifestations of psoriasis include lesions of small, whitish papules, red and white plaques that follow skin lesions and bright red patches, all of which may also be associated with angular cheilitis, geographic tongue lesions and a fissured tongue. ${ }^{42}$ Whether psoriasis can manifest solely in the oral mucosa has been a matter of debate for years. The benefits of our relatively large, matched-cohort design used in this study allowed us to also detect associations between rare diseases such as autoimmune diseases.

Based on genome-wide association studies, both asthma and autoimmune diseases are associated with several single-nucleotide polymorphisms in the human 17q12-21 locus. ${ }^{43}$ Although rare and difficult to diagnose, some case reports suggest that an intraoral form of psoriasis exists. ${ }^{44}$ Moreover, studies have shown shared genetic variants of asthma and autoimmune diseases, ${ }^{4}$ possibly reflecting an increased co-existence of asthma and psoriasis compared with controls. Asthma and psoriasis also share certain comorbidities such as cardiovascular diseases, depression, diabetes and obesity. ${ }^{45}$

In line with our findings for psoriasis, another autoimmune disease, lichen planus, emerged as one of the most common dermatological diseases among asthmatics in our study. The clinical features of oral lichen planus typically include pain and burning in the mouth induced by spicy or acidic foods due to lesions in the mucosa. Clinical presentations of oral lichen planus consist of reticular, erosive, plaque-like and bullous lesions, which can occur individually or in combination. Frequently asymptomatic, reticular oral lichen planus is, however, the most common type of lichen planus. ${ }^{46}$ To our knowledge, no previous studies examined the association between lichen planus and asthma.

This study has several strengths and limitations. The strengths of this study include the population-based, 
matched-cohort design and the inclusion of asthma diagnoses confirmed through lung function tests. This study also benefits from its long follow-up period. Conversely, one limitation to this study stems from the lack of primary care data, from which typical dental problems such as dental caries are normally treated. We also note that the possible causal relationship between asthma and oral health conditions may be confounded by asthma medications. Medications commonly used to treat asthma, such as $\beta_{2}$-agonists and inhaled steroids, may promote caries, dental erosion, periodontal disease, erosion and oral candidiasis. $^{25}$

We calculated HRs to measure the difference between asthmatic and non-asthmatic patients. However, using HRs, roughly interpreted as the incidence rate ratio, is not completely unproblematic. The use of HRs to indicate a causal relationship is risky for two reasons: first, HR may change over time and, second, HR has a built-in selection bias. ${ }^{47}$ We acknowledge the possibility of a detection bias due to the more intensive use of healthcare services by asthmatics (and people with any moderate to severe chronic disease) than non-asthmatics, potentially affecting our results. For some comorbidities, uncertainty (wide CIs) regarding the magnitudes of the observed relative differences and a limited statistical power precluding any potentially existing associations should be considered when interpreting our results.

Finally, one of the most common oral health problems, periodontitis, carries a two-way relationship with diabetes mellitus, and is presumably associated with severe asthma in adults. ${ }^{48}$ Periodontitis is diagnosed and primarily treated in primary care settings. The incidence of this chronic inflammatory disease of the tissue surrounding the teeth thus cannot be investigated with this dataset. The clinical features of cases were not available given the register-based study design. In cases of herpes zoster and psoriasis, ICD-10 codes do not distinguish between anatomical sites of disease manifestation. However, to our knowledge, the incidence of oral manifestations of these diseases remains unclear, and is therefore important to take into account for each case.

\section{CONCLUSIONS}

Adult asthmatics experience a higher risk for an oralmanifesting disease. Viral and fungal infections represented the most common oral disease among asthmatics, while the risk for a benign tumour or dermatological disease was also higher among adult asthmatics. Identifying the most common asthma-related oral diseases may result in an early diagnosis and better management of comorbid conditions as well as the overall health of asthmatics. As such, dental professionals are an important part of healthcare teams given their expertise in detecting abnormalities in the oral cavity of asthmatic patients.

\section{Author affiliations}

${ }^{1}$ Haartman Institute, University of Helsinki, Helsinki, Uusimaa, Finland
${ }^{2}$ Department of Public Health, University of Helsinki, Helsinki, Uusimaa, Finland ${ }^{3}$ Allergy Centre, Tampere University Hospital, Tampere, Finland

${ }^{4}$ Faculty of Medicine and Health Technology, Tampere University, Tampere,

Pirkanmaa, Finland

${ }^{5}$ Haartman Instutute, Helsingin yliopisto, Helsinki, Uusimaa, Finland

${ }^{6}$ HUSLAB, HUS, Helsinki, Uusimaa, Finland

${ }^{7}$ National Institute for Health and Welfare, Helsinki, Finland

${ }^{8}$ Skin and Allergy Hospital, Helsinki, Uusimaa, Finland

${ }^{9}$ Medicum, Haartman Institute, University of Helsinki, Helsinki, Uusimaa, Finland

Acknowledgements We thank the following people for their valuable contributions: Professor Arpo Aromaa, Heini Huhtala MSc, Professor Timo Klaukka and Professor Markku M. Nieminen.

Contributors RL, ST-S, JK and JH contributed to data acquisition, analysis, interpretation and design, and revised the manuscript for critical intellectual content. AB, RR and JP critically revised the manuscript. All authors agree to be accountable for all aspects of the work. RL is the guarantor of this manuscript.

Funding This study was supported by grants from the Finnish Allergy Research Foundation, the Finnish Association of Otorhinolaryngology and Head and Neck Surgery, the Finnish Medical Foundation, the Finnish Society of Allergology and Immunology, the Foundation of the Finnish Anti-Tuberculosis Association, the Jane and Aatos Erkko Foundation, the Paulo Foundation, the Research Foundation of Pulmonary Diseases, the Tampere Tuberculosis Foundation, the Väinö and Laina Kivi Foundation, the Yrjö Jahnsson Foundation and Rehabilitation Funds of the Finnish Social Insurance Institution.

Competing interests None declared.

Patient and public involvement Patients and/or the public were not involved in the design, or conduct, or reporting, or dissemination plans of this research.

Patient consent for publication Not applicable.

Ethics approval Approval for the study was obtained from the ethical committee at Tampere University Hospital (R15030) and written informed consent was obtained from all subjects.

Provenance and peer review Not commissioned; externally peer reviewed.

Data availability statement No data are available. The data that support the findings of this study areavailable from Statistics Finland and the the National Institute for Health and Welfare, but restrictions apply to the availability of these data, which wereused under licence for the current study, and so are not publicly available. Data are,however, available from the authors on reasonable request and with permission ofStatistics Finland and the National Institute for Health and Welfare.

Open access This is an open access article distributed in accordance with the Creative Commons Attribution Non Commercial (CC BY-NC 4.0) license, which permits others to distribute, remix, adapt, build upon this work non-commercially, and license their derivative works on different terms, provided the original work is properly cited, appropriate credit is given, any changes made indicated, and the use is non-commercial. See: http://creativecommons.org/licenses/by-nc/4.0/.

Author note JH and ST-S shared last authorship.

\section{ORCID iDs}

Riikka Lemmetyinen http://orcid.org/0000-0003-0007-9866

Jari Haukka http://orcid.org/0000-0003-1450-6208

Sanna Toppila-Salmi http://orcid.org/0000-0003-0890-6686

\section{REFERENCES}

1 Papi A, Brightling C, Pedersen SE, et al. Asthma. Lancet 2018;391:783-800.

2 Lundbäck B, Backman H, Lötvall J, et al. Is asthma prevalence still increasing? Expert Rev Respir Med 2016;10:39-51.

3 D'Amato M, Cecchi L, Annesi-Maesano I, et al. News on climate change, air pollution, and allergic triggers of asthma. J Investig Allergol Clin Immunol 2018;28:91-7.

4 Das S, Miller M, Broide DH. Chromosome 17q21 genes ORMDL3 and GSDMB in asthma and immune diseases. Adv Immunol 2017;135:1-52.

5 Kaur R, Chupp G. Phenotypes and endotypes of adult asthma: moving toward precision medicine. J Allergy Clin Immunol 2019;144:1-12. 
6 Trivedi M, Denton E, Turner S. Asthma in children and adults-what are the differences and what can they tell us about asthma? Front Pediatr 2019;7:256.

7 de Nijs SB, Venekamp LN, Bel EH. Adult-onset asthma: is it really different? Eur Respir Rev 2013;22:44-52.

8 Amaral R, Fonseca JA, Jacinto T, et al. Having concomitant asthma phenotypes is common and independently relates to poor lung function in NHANES 2007-2012. Clin Transl Allergy 2018;8:13.

9 Moore WC, Meyers DA, Wenzel SE, et al. Identification of asthma phenotypes using cluster analysis in the severe asthma research program. Am J Respir Crit Care Med 2010;181:315-23.

10 Haldar P, Pavord ID, Shaw DE, et al. Cluster analysis and clinical asthma phenotypes. Am J Respir Crit Care Med 2008;178:218-24.

11 Schoettler N, Strek ME. Recent advances in severe asthma: from phenotypes to personalized medicine. Chest 2020;157:516-28.

12 Veenendaal M, Westerik JAM, van den Bemt L, et al. Age- and sex-specific prevalence of chronic comorbidity in adult patients with asthma: a real-life study. NPJ Prim Care Respir Med 2019;29:14.

13 Lemmetyinen RE, Karjalainen JV, But A, et al. Higher mortality of adults with asthma: a 15-year follow-up of a population-based cohort. Allergy 2018;73:1479-88.

14 Kauppi P, Linna M, Jantunen J. Chronic comorbidities contribute to the burden and costs of persistent asthma. Mediators Inflamm 2015;2015:1-7.

15 Boulet L-P, Boulay Marie-Ėve. Asthma-related comorbidities. Expert Rev Respir Med 2011:5:377-93.

16 Weatherburn CJ, Guthrie B, Mercer SW, et al. Comorbidities in adults with asthma: population-based cross-sectional analysis of 1.4 million adults in Scotland. Clin Exp Allergy 2017;47:1246-52.

17 Alavaikko S, Jaakkola MS, Tjäderhane L, et al. Asthma and caries: a systematic review and meta-analysis. Am J Epidemiol 2011:174:631-41.

18 Kwon HJ, Bang DW, Kim EN, et al. Asthma as a risk factor for zoster in adults: A population-based case-control study. J Allergy Clin Immunol 2016;137:1406-12.

19 Lønnberg AS, Skov L, Skytthe A, et al. Asthma in patients with psoriasis. Br J Dermatol 2015;172:1660-1.

20 Nair P, Gharote H, Singh P, et al. Herpes zoster on the face in the elderly. BMJ Case Rep 2014;2014:bcr2013200101.

21 Thomas MS, Parolia A, Kundabala M, et al. Asthma and oral health: a review. Aust Dent J 2010;55:128-33.

22 Wang J, Ke R, Shi W, et al. Association between psoriasis and asthma risk: a meta-analysis. Allergy Asthma Proc 2018;39:103-9.

23 Boehncke W-H, Schön MP. Psoriasis. Lancet 2015;386:983-94.

24 Ghapanchi J, Rezazadeh F, Kamali F, et al. Oral manifestations of asthmatic patients. J Pak Med Assoc 2015;65:1226-7.

25 Gani F, Caminati M, Bellavia F, et al. Oral health in asthmatic patients: a review asthma and its therapy may impact on oral health. Clin $\mathrm{Mol}$ Allergy 2020;18:22

26 Wee $\mathrm{JH}$, Park MW, Min C, et al. Poor oral health is associated with asthma, allergic rhinitis, and atopic dermatitis in Korean adolescents. Medicine 2020;99:e21534.

27 Gaeckle NT, Pragman AA, Pendleton KM, et al. The oral-lung axis: the impact of oral health on lung health. Respir Care 2020;65:1211-20.
28 Ryberg M, Möller C, Ericson T. Saliva composition and caries development in asthmatic patients treated with beta 2-adrenoceptor agonists: a 4-year follow-up study. Scand J Dent Res 1991;99:212-8

29 Hyyppä T. Gingival IgE and histamine concentrations in patients with asthma and in patients with periodontitis. J Clin Periodontol 1984;11:132-7

30 Peters U, Dixon AE, Forno E. Obesity and asthma. J Allergy Clin Immunol 2018;141:1169-79.

31 Pasternack R, Huhtala H, Karjalainen J. Chlamydophila (Chlamydia) pneumoniae serology and asthma in adults: a longitudinal analysis. $J$ Allergy Clin Immunol 2005;116:1123-8.

$32 \mathrm{NCl}$ Dictionary of Cancer Terms - National Cancer Institute. Definition of pack year, 2011. Available: https://www.cancer.gov/publications/ dictionaries/cancer-terms/def/pack-year [Accessed 12 Apr 2021]

33 R Core Team. R core team (2019). R: a language and environment for statistical computing, 2019. Available: https://www.r-project.org/

34 Peng $\mathrm{Y}-\mathrm{H}$, Fang $\mathrm{H}-\mathrm{Y}$, Wu B-R, et al. Adult asthma is associated with an increased risk of herpes zoster: a population-based cohort study. $J$ Asthma 2017;54:250-7.

35 Marra F, Parhar K, Huang B, et al. Risk factors for herpes zoster infection: a meta-analysis. Open Forum Infect Dis 2020;7.

36 John AR, Canaday DH. Herpes zoster in the older adult. Infect Dis Clin North Am 2017;31:811-26.

37 Mortazavi H, Safi Y, Baharvand M, et al. Diagnostic features of common oral ulcerative lesions: an updated decision tree. Int J Dent 2016;2016:1-14.

38 Edwards MR, Strong K, Cameron A, et al. Viral infections in allergy and immunology: how allergic inflammation influences viral infections and illness. J Allergy Clin Immunol 2017;140:909-20.

39 Makris S, Johnston S. Recent advances in understanding rhinovirus immunity [version 1; peer review: 4 approved]. F1000Research 2018;7.

40 Hirano T, Matsunaga K. Late-onset asthma: current perspectives. J Asthma Allergy 2018;11:19-27.

41 Brown JE. Salivary gland diseases: presentation and investigation. Prim Dent J 2018;7:48-57.

42 Dreyer LN, Brown GC. Oral manifestations of psoriasis. clinical presentation and management. N Y State Dent J 2012;78:14-18.

43 Ustiugova AS, Korneev KV, Kuprash DV, et al. Functional SNPs in the human autoimmunity-associated locus 17q12-21. Genes 2019;10:77.

44 Mattsson U, Warfvinge G, Jontell M. Oral psoriasis-a diagnostic dilemma: a report of two cases and a review of the literature. Oral Surg Oral Med Oral Pathol Oral Radiol 2015;120:e183-9.

45 Takeshita J, Grewal S, Langan SM. Psoriasis and comorbid diseases: epidemiology. J Am Acad Dermatol 2017;76:377-90.

46 Sankar V, Noujeim M. Oral manifestations of autoimmune and connective tissue disorders. Atlas Oral Maxillofac Surg Clin NA 2017;25:113-26.

47 Hernán MA. The hazards of hazard ratios. Epidemiology 2010;21:13-15.

48 Zhou X, Zhang W, Liu X, et al. Interrelationship between diabetes and periodontitis: role of hyperlipidemia. Arch Oral Biol 2015;60:667-74

49 Soledade-Marques KR, Gomes-Filho IS, da Cruz SS, et al. Association between periodontitis and severe asthma in adults: a case-control study. Oral Dis 2018;24:442-8. 